\title{
SABERES E PRÁTICAS DO PEDAGOGO COMO COORDENADOR PEDAGÓGICO
}

\author{
KNOWLEDGE AND PRACTICES OF \\ THE EDUCATOR AS AN EDUCATIONAL \\ COORDINATOR
}

Raquel Quirino ${ }^{1}$

"Quem educa o educador?"

(MARX, Karl. III Tese contra Feuerbach, 1978, p. 51).

${ }^{1}$ Professora adjunta

do CEFET-MG,

no Programa de

Pós-Graduação em

Educação Tecnológica

(PPGET) e no Programa

Especial de Formação

Pedagógica de

Docentes (PEFPD)

\section{RESUMO}

O presente artigo visa suprir uma lacuna existente nas produções acadêmicas acerca dos saberes e práticas necessários ao pedagogo para atuação na coordenação pedagógica das escolas. Problematizando questões diversas sobre essa temática, busca promover uma reflexão profícua nos meios acadêmicos, sobretudo nas faculdades de educação, agências encarregadas da formação do pedagogo. A coordenação pedagógica está relacionada a um cargo ou a uma função? O termo "coordenador pedagógico" constituiuse, apenas, como atenuante para a conotação negativa do termo "supervisor pedagógico", aquele que exercia mera atividade controladora da prática pedagógica docente? $\mathrm{O}$ que se espera hoje da atuação dos profissionais que coordenam a prática pedagógica dos/as professores/as? Quais saberes devem possuir? Qual o seu principal papel? Pode-se considerar 
o coordenador pedagógico o "educador do educador"? Esperase contribuir para o debate e evidenciar os saberes e práticas demandadas a esse profissional e que devem fazer parte de sua formação profissional.

Palavras-chave: Coordenação pedagógica. Formação do pedagogo. Saberes e práticas pedagógicas.

\section{INTRODUÇÃO}

Pesquisas e estudos diversos ${ }^{1}$ acerca dos saberes docentes são recorrentes no meio acadêmico, sobretudo quando se trata da formação de professores. No entanto, são escassas as produções científicas que visam à discussão dos saberes e práticas necessários à formação do pedagogo para atuação no cargo de coordenador pedagógico.

O presente artigo visa problematizar essa questão e promover uma reflexão profícua sobre a formação do pedagogo para a atuação na coordenação pedagógica das escolas, sobretudo exercendo atividades direcionadas à formação continuada dos professores. A coordenação pedagógica está relacionada a um cargo ou a uma função? O termo "coordenador pedagógico" constituiu-se, apenas, como atenuante para a conotação negativa do termo "supervisor pedagógico", aquele que exercia uma mera atividade controladora da prática pedagógica

${ }^{1}$ Saviani (1996), Tardif (2002), Pimenta (2002), Freire (1996), Therrien (2004), Gauthier (2013) Almeida e Biajone (2007), dentre outros. 
docente? (SANTOS e OLIVEIRA, 2010, p. 4). O que se espera hoje da atuação dos profissionais que coordenam a prática pedagógica dos/as professores/as? Quais saberes devem possuir? Qual o seu principal papel?

Para Vasconcellos (2002), o que se espera hoje da esfera de atuação e preocupação da coordenação pedagógica "envolve questões de currículo, construção do conhecimento, aprendizagem, relações interpessoais, ética, disciplina, avaliação da aprendizagem, relacionamento com a comunidade, recursos didáticos, entre outros" (p. 85). O foco de sua atenção é o trabalho de formação tanto individual quanto coletivo, pois "deve contribuir com o aperfeiçoamento profissional de cada um dos professores e, ao mesmo tempo, ajudar a constituí-los enquanto grupo" (p. 88).

Sob esse ponto de vista, o trabalho do/a coordenador/a pedagógico/a se afasta da postura do controle burocrático em direção ao/à educador/a. Assim, essa função, conforme alerta Alarcão (2001, p. 13), passa a ser compreendida como um "processo em que um professor, em princípio mais experiente e mais informado, orienta outro professor ou candidato a professor no seu desenvolvimento humano e profissional" (grifo meu). O que se pode inferir, então, é que a experiência e o domínio dos saberes docentes são imprescindíveis para quem almeja educar o/a educador/a.

Mas o que realmente encontramos nas escolas ${ }^{2}$ atualmente?

${ }^{2}$ Serão tratadas aqui apenas as escolas cujo cargo na coordenação pedagógica é exercido por licenciados em Pedagogia contratados via concurso público. 
Em sua grande maioria, o cargo de coordenador/a pedagógico/a é exercido por profissionais licenciados em Pedagogia, contratados/as via concurso público. As provas seletivas basicamente avaliam saberes conceituais e teóricos acerca da atividade docente, mas não dão conta de avaliar a experiência e os saberes constituídos por esses profissionais. Assim, constatamos, com certa frequência, coordenadores/ as pedagógicos/as recém-formados/as, gestados/as em uma formação profissional inadequada e aligeirada ${ }^{3}$, coordenando o trabalho pedagógico de professores/as mais experientes e que já se encontram há anos à frente da sala de aula.

Por não terem a definição clara do seu papel e, mais ainda, por não possuírem os saberes constituintes e constitutivos da docência, passam a exercer atividades que não deveriam fazer parte da sua atuação nas escolas. Parafraseando Vasconcellos (2002), passam a ser: fiscal de professor; dedo-duro (aquele que entrega os professores para a direção); pombo-correio (que leva recado da direção para os professores e vice-versa); coringa/quebra-galho/salva-vidas (ajudante de direção, auxiliar de secretaria, enfermeiro, assistente social etc.); tapaburaco (substituto de professor, diretor, vice-diretor etc.); burocrata (preenchedor de relatórios, gráficos, estatísticas etc.); profissional de seis pernas (que fica o dia todo sentado na própria sala, longe da prática e dos desafios efetivos dos educadores); dicário (que tem dicas e soluções para todos os problemas com uma fonte inesgotável de técnicas e receitas prontas); generalista (que entende quase nada de quase tudo);

${ }^{3}$ Sobre a deficiência da formação inicial dos professores, ver: Piconez, 1991; Pimenta, 1994 e 1996; Leite, 1995. 
corpo de bombeiro (que é chamado apenas para resolver problemas e apagar os "incêndios" ocorridos na escola), dentre outras atividades tão inúteis quanto a presença do coordenador pedagógico na instituição pode vir a ser.

Essa indefinição de papéis e essa carência dos saberes necessários à atuação são fontes constantes de desentendimentos e crises entre coordenadores e professores, dificultando tanto a atuação de uns quanto dos outros, comprometendo o processo de ensino-aprendizagem e alterando de forma negativa o clima da escola. A figura da coordenação exercendo uma super-visão à moda antiga, como expressão do desejo de controle total dos movimentos dos outros, a exemplo do "panóptico de Bentham", descrito por Foucault (1977, p. 177) ${ }^{4}$, distorce a real necessidade desse profissional para conduzir de forma satisfatória as ações docentes e contribuir para a formação continuada dos/as professores/as. Mas, mais ainda que saber com clareza o seu papel na coordenação da prática educativa, o/a coordenador/a pedagógico/a precisa possuir os saberes necessários à docência, a fim de se tornar um/a verdadeiro/a educador/a do/a educador/a, pois não se pode ensinar aquilo que não se sabe.

\footnotetext{
${ }^{4}$ O panóptico de Bentham é um projeto arquitetônico descrito por Foucault no qual há uma construção em anel e, no centro, uma torre vazada com largas janelas, de onde um "supervisor" pode ver sem parar tudo o que acontece nas celas, onde está um louco, um doente, um condenado, um operário e um escolar.
} 


\section{SABERES E PRÁTICAS DA COORDENAÇÃO DO TRABALHO PEDAGÓGICO}

A principal questão levantada neste artigo refere-se ao papel do/a coordenador/a pedagógico/a como educador do/a educador/a, os saberes necessários a serem mobilizados por esses profissionais na coordenação da prática educativa nas escolas, assim como a dimensão epistemológica de sua prática profissional.

[...] chamamos de epistemologia da prática profissional o estudo do conjunto dos saberes utilizados realmente pelos profissionais em seu espaço de trabalho cotidiano para desempenhar todas as suas tarefas (TARDIF, 2002, p. 255. Grifos do autor).

Para melhor compreensão do significado da palavra "saber", consideramos também o conceito proposto por Tardif (2000, p. 10-11):

[...] damos aqui à noção de "saber" um sentido amplo, que engloba os conhecimentos, as competências, as habilidades (ou aptidões) e as atitudes, isto é, aquilo que muitas vezes foi chamado de saber, saber-fazer e saber ser.

Segundo Saviani (1996), o processo educativo é um fenômeno complexo, tanto nas formas de organização e efetivação quanto nas representações que dele fazem seus agentes. Assim, os saberes nele envolvidos também se revestem da aparência de um caos irredutivel, mesmo para aqueles que participam diretamente de sua efetivação. Há conhecimentos e um saberfazer próprios, saberes curriculares, teóricos e disciplinares da 
formação profissional inicial, saberes da própria experiência e saberes tácitos, íntimos e pessoais.

A partir da diversidade e do pluralismo dos saberes elencados por diversos autores estudiosos da formação docente (tais como ZABALA, 1998; ARROYO, 2000; ENRICONE, 2004; PIMENTA, 2002; VASCONCELLOS, 2002, dentre outros; assim como os saberes descritos nos Referenciais para Formação de Professores, BRASIL, 2002), certas características comuns, que podem constituir o corpus dos saberes da coordenação pedagógica em suas atividades nas escolas, permitem-nos arriscar uma categorização dos saberes - aqueles que todo/a coordenador/a pedagógico/a deve dominar.

Apenas por questões didáticas e para facilitar a reflexão em torno de cada saber, dividimos em dois grandes grupos:

\section{- os saberes profissionais;}

\section{- os saberes experienciais.}

Apoiamo-nos, sobretudo, nas categorias propostas por Saviani (1996), no ensaio "Os saberes implicados na formação do educador", no qual o autor aponta um conjunto de saberes que, em princípio, todo/a educador/a deve dominar e, por isso, integra o processo de formação desses profissionais.

Também, para a apresentação das categorias de saberes não preconizadas por Saviani (1996), utilizamos os trabalhos de Tardif (2002), sobre a formação profissional do/a educador/a, e as reflexões de Freire (1996), sobre os "saberes necessários à prática educativa", que, segundo o autor, "são saberes 
demandados pela prática educativa em si mesma, qualquer que seja a opção política do educador ou educadora" (FREIRE, 1996, p. 23).

Embora os/as autores/as citados abordem os conhecimentos, saberes, saber-fazer, saber ser, competências e habilidades que servem de base para a formação docente, ou seja, para a formação do profissional que atua diretamente em sala de aula, entendemos ser de grande valia a discussão desses estudos com relação à atuação da coordenação pedagógica. Uma vez que, como educadores/as do/a educador/a e agentes mediadores e catalizadores $^{5}$ da prática educativa, todo/a coordenador/a pedagógico/a deve ser possuidor dos saberes docentes.

Em sua categorização de saberes do/a educador/a, Saviani (1996) diferencia sofia, o saber decorrente da experiência de vida, de episteme, o saber decorrente de processos sistemáticos de construção de conhecimentos. Segundo o próprio autor, considerando-se os saberes implicados na formação do/a educador/a sob o ponto de vista da forma, sofia e episteme atravessam indistintamente os diferentes tipos de saberes, ainda que com ênfases diferenciadas. No entanto, a forma episteme marca também os saberes experienciais, assim como a forma sofia não está ausente do modo como o/a educador/a apreende os saberes profissionais. A experiência e a prática, na medida em que se configuram como saberes,

\footnotetext{
${ }^{5}$ Aproveitamos aqui a analogia proposta por Vasconcellos (2002, p. 88), na qual o/a coordenador/a pedagógico/a atua como o catalizador na reação química: não entra na reação, embora seja seu elemento desencadeador ou acelerador.
} 
implicam necessariamente certo grau de sistematização que não pode ser desconsiderado na forma como se constroem os saberes acadêmicos ou profissionais.

Conforme Saviani (1996, p. 151), os saberes experienciais não são um tipo de saber diferenciado, isso porque "não se trata aí de um conteúdo diferenciado dos demais, mas de uma forma que pode estar referida indistintamente aos diferentes tipos de saber".

\section{Saberes profissionais}

A categoria saberes profissionais, na qual prevalecem os processos sistemáticos para a aquisição dos saberes, é proposta por Saviani (1996) com as seguintes subcategorias:

- $\quad$ saberes pedagógicos;

- $\quad$ saberes didático-curriculares;

- $\quad$ saberes específicos.

Embora sendo analisado na categoria dos saberes profissionais, conforme preconiza Saviani (1996), consideramos aqui o saber didático-curricular numa posição intermediária, pois requer certo grau de sistematização, assim como a experiência prática.

Para Tardif (2002, p. 36), saberes profissionais são o conjunto de saberes transmitidos pelas instituições de formação, o conhecimento socialmente produzido e que integra os currículos dos cursos, oriundos das ciências da natureza, das ciências humanas, das exatas, das artes ou das técnicas ou de 
outras modalidades. Nessa perspectiva, esses conhecimentos se transformam em saberes destinados à formação científica ou erudita dos/as educadores/as. Também chamado de saber acadêmico, é adquirido por meio da formação inicial ou contínua, em cursos de graduação e pós-graduação, nos quais há o contato direto com as ciências da educação.

Porém, Tardif (2002) revela que 30 anos de pesquisa mostram uma relação de distância entre os saberes profissionais e os conhecimentos universitários.

Essa distância pode assumir diversas formas, podendo ir da ruptura à rejeição da formação teórica pelos profissionais, ou então assumir formas mais atenuadas, como adaptações, transformações, seleção de certos conhecimentos universitários a fim de incorporá-los à prática. Desse ponto de vista, a prática profissional nunca é um espaço de aplicação dos conhecimentos universitários. Ela é, na melhor das hipóteses, um processo de filtração que os dilui e os transforma em função das exigências do trabalho; ela é, na pior das hipóteses, um muro contra o qual vêm se jogar e morrer conhecimentos universitários considerados inúteis, sem relação com a realidade do trabalho diário nem com os contextos concretos de exercício da função (TARDIF, 2002, p. 257).

A afirmação de Tardif (2002) é corroborada por Pimenta (2002, p. 16), pois

[...] os cursos de formação, ao desenvolverem um currículo formal com conteúdos e atividades de estágios distanciados da realidade das escolas, numa perspectiva burocrática e cartorial que não dá conta de captar as contradições presentes na prática social de educar, pouco têm contribuído para gestar uma nova identidade do profissional docente. [...] Esses programas têm se mostrado pouco eficientes para 
alterar a prática docente e, consequentemente, as situações de fracasso escolar, por não tomarem a prática docente e pedagógica escolar nos seus contextos.

A esses saberes "produzidos pelas ciências da educação e sintetizados nas teorias educacionais, visando articular os fundamentos da educação com as orientações que se imprimem ao trabalho educativo", Saviani (1996, p. 149) denomina saberes pedagógicos.

Também para Tardif (2002), os saberes pedagógicos apresentam-se como doutrinas ou concepções provenientes de reflexões sobre a prática educativa no sentindo amplo do termo, reflexões racionais e normativas que conduzem a sistemas mais ou menos coerentes de representação e de orientação da atividade educativa.

Para esses autores, os saberes pedagógicos articulam-se com as ciências da educação, sendo até mesmo difícil distinguilos entre si, e traduzem também as doutrinas pedagógicas dominantes, incorporando-as à formação profissional dos/ as educadores/as e fornecendo um arcabouço ideológico à profissão, algumas formas de saber-fazer e algumas técnicas.

Em Saviani (1996), encontramos a denominação saber didáticocurricular para a categoria em que estão compreendidos os saberes técnicos relativos às formas de organização e realização da atividade educativa. Em sentido mais específico, o domínio do saber-fazer implica não apenas os procedimentos técnicos metodológicos, mas também a dinâmica do trabalho pedagógico, como uma estrutura articulada de agentes, conteúdos, instrumentos e procedimentos que se 
movimentam no espaço e no tempo pedagógicos, visando atingir os objetivos propostos pelo processo educativo.

Outra categoria apresentada por Saviani (1996) são os saberes específicos, aqueles que o/a profissional não deve ignorar e que são de fundamental importância para a sua atuação. Saviani (1996) fala desses saberes como aqueles correspondentes às disciplinas que serão ensinadas pelo/a professor/a (Matemática, Português, História e outras). Tardif (2002) chama esses saberes específicos de saberes disciplinares e curriculares. Os primeiros correspondem aos conteúdos dos diversos campos do conhecimento de que dispõe a nossa sociedade, tais como se encontram integrados no interior dos cursos, e os segundos estão sob a forma de programas escolares (objetivos, conteúdos, métodos), os quais os/as professores/as devem aprender a aplicar.

Os saberes específicos a serem utilizados pelo/a coordenador/a pedagógico/a não se referem aos conteúdos das disciplinas ministradas pelos/as professores/as, mas a uma gama de conhecimentos necessários à gestão educacional, tais como conhecer o ambiente externo e interno da instituição na qual trabalha, as estruturas formal e informal, a cultura e o clima organizacionais, bem como as variáveis que os determinam (FALCÃO FILHO, 2000). Tais saberes devem ser buscados na educação continuada, em cursos direcionados para a sua área de atuação e construídos na sua experiência pessoal e profissional. 


\section{Saberes experienciais}

Ainda nas categorias propostas por Saviani (1996) e também nas reflexões de Tardif (2002), os saberes experienciais são tratados em duas subcategorias:

\section{- saber comportamental-atitudinal;}

- $\quad$ saber crítico-contextual.

Conforme já citado, para Saviani (1996, p. 151), os saberes da experiência não podem ser considerados como "um tipo de saber ao lado dos demais", isto porque, para o autor, não se trata de um conteúdo diferenciado, mas de uma forma que pode estar referida de maneira indistinta aos diferentes tipos de saber. Porém, Tardif (2002) considera que os/as educadores/ as na prática de suas funções e de sua profissão desenvolvem alguns saberes específicos, baseados no trabalho cotidiano e no conhecimento do meio e que devem ser investigados. Esses saberes, segundo Tardif (2002), brotam da experiência e são por ela validados.

Eles incorporam-se à experiência individual e coletiva sob a forma de habitus e de habilidades, de saberfazer e de saber-ser. Podemos chamá-los de saberes experienciais ou práticos (TARDIF, 2002, p. 39).

Também o início da carreira do/a pedagogo/a como coordenador pedagógico ou a mudança de função do/a professor/a para coordenador/a são acompanhados de uma fase crítica. É a partir das certezas e das condicionantes da experiência anterior prática que o/a coordenador/a pedagógico/a articula a sua formação acadêmica (o/a 
pedagogo/a novato/a, sua experiência como aluno/a; e o/a professor/a, sua experiência docente). Muita coisa se aprende com a prática, pela experiência, tateando e descobrindo, em suma, na execução do próprio trabalho. Outra fonte de aprendizagem prática no trabalho é a experiência dos outros, dos pares, dos superiores, dos colegas de outros segmentos da escola, em suma, de toda a comunidade escolar.

Com relação a comportamentos e atitudes, Saviani (1996) denomina-os saberes comportamentais-atitudinais. Essa categoria compreende o domínio dos comportamentos e vivências necessários ao trabalho educativo:

\begin{abstract}
Abrange atitudes e posturas inerentes ao papel atribuído ao educador, tais como disciplina, pontualidade, coerência, clareza, justiça e eqüidade, diálogo, respeito às pessoas dos educandos, atenção às suas dificuldades etc. Trata-se de competências que se prendem à identidade e conforma a personalidade do educador (SAVIANI, 1996, p. 148).
\end{abstract}

O autor enfatiza a necessidade de se ter uma atitude baseada no aprender a aprender e de saber transformar cada momento e experiência vividos em oportunidades de aprendizado. Também reconhece a importância da criatividade e a curiosidade como partes integrantes do repertório de saberes do/educador/a, o que, para Paulo Freire (1996), é chamada de "curiosidade epistemológica":

A curiosidade como inquietação indagadora, como inclinação ao desvelamento de algo, como pergunta verbalizada ou não, como procura de esclarecimento, como sinal de atenção que sugere alerta faz parte integrante do fenômeno vital. Não haveria criatividade sem a curiosidade que nos move 
e nos põe pacientemente impacientes diante do mundo que não fizemos, acrescentando a ele algo que fazemos (FREIRE, 1996, p. 35).

O aprendizado oriundo das experiências e do contato com os colegas e alunos/as, aliado à criatividade e à curiosidade, possibilita fazer a transposição dos saberes pedagógicos e didático-curriculares, adquiridos nos meios acadêmicos, em especial, nos cursos de Pedagogia e de formação docente, para prática da coordenação pedagógica, sendo também de fundamental importância para a construção dos saberes específicos necessários ao exercício de suas atividades.

Também a capacidade de comunicar-se com eficácia, tanto oralmente quanto por escrito, e de utilizar as tecnologias da informação e de comunicação, são saberes considerados de grande importância.

No tratado sobre "os saberes necessários à prática educativa", Freire (1996) auxilia na compreensão dos saberes comportamentais quando aborda a necessidade do/a educador/a ter respeito pelos/as educandos/as; comprometerse com a ética e a humildade; ter plena consciência do seu inacabamento profissional; comprometimento com seus valores e princípios; segurança, competência profissional e generosidade, sobretudo na reflexão crítica sobre a própria prática.

Esse saber crítico trata de um saber relativo à compreensão das condições sócio-históricas que determinam a tarefa educativa. Segundo Saviani (1996), o/a educador/a deve compreender o movimento da sociedade, identificando suas características 
básicas e as tendências de sua transformação, de modo a detectar as necessidades presentes e futuras a serem atendidas pelo processo educativo sob sua responsabilidade. É necessária, então, a compreensão do contexto com base no qual e para o qual se desenvolve o trabalho educativo, traduzida aqui na categoria do saber crítico-contextual.

Se a compreensão do contexto no qual e para o qual se desenvolve o trabalho educativo é de vital importância para o/a educador/a na prática educativa nas salas de aula, já para o/a coordenador/a pedagógico/a, ela se torna imprescindível, por esse profissional exercer funções de liderança e se constituir em "educador/a do/a educador/a". Apesar das dificuldades e interfaces do trabalho de coordenação, que muitas vezes abrange aspectos burocráticos e organizacionais, a dimensão humana do seu trabalho e a importância de uma postura ética voltada para os interesses dos/as educandos/as e dos/as professores/as devem ser o mote de atuação do/a coordenador/a.

O coordenador, ao mesmo tempo em que acolhe e engendra, deve ser questionador, desequilibrador, provocador, animando e disponibilizando subsídios que permitam o crescimento do grupo. Tem, portanto, um papel importante na formação dos educadores [...] em termos de abertura para um novo paradigma, podemos nos propor passar de "super" visão para "outra" - visão! (VASCONCELLOS, 2002, p. 89. Grifos do autor).

Devido ao papel de líder, coordenador/a e formador/a docente, há uma grande ênfase na necessidade do desenvolvimento dos saberes comportamentais-atitudinais e crítico-contextuais por parte da coordenação pedagógica. Os saberes profissionais - 
ainda que imprescindíveis para a atuação-ficam condicionados à "prática, que os confronta e os reelabora" (PIMENTA, 2002, p. 26).

\section{OUTROS SABERES DA DOCÊNCIA E O/A COORDENADOR/A PEDAGÓGICO/A}

Tomasi (2004, p. 155), em estudos sobre a constituição dos saberes e das competências, reconhece que a experiência é uma das maiores fontes de conhecimento para qualquer trabalhador/a. O autor também relaciona dois grandes problemas inerentes à construção da competência profissional e que podemos assemelhar às dificuldades enfrentadas pelos/as coordenadores/as pedagógicos/as na prática diária: o primeiro refere-se ao "aprender a aprender", em que cada situação de trabalho torna-se uma oportunidade constitutiva do saber, e o segundo, à capacidade de transferir os saberes de um domínio de atuação para outro.

Como alunos/as dos cursos de Pedagogia e/ou de formação inicial e continuada, os/as coordenadores/as pedagógicos/a já adquirem um aprendizado fecundo sobre a atuação docente, porém não suficiente para uma prática bem-sucedida. 0 exercício constante da "curiosidade epistemológica", o "aprender a aprender" e a humildade de aprender com os/as professores/a mais experientes que coordenam é fundamental para seu desenvolvimento profissional e para uma prática eficaz. Por outro lado, o/a professor/a já experiente em sala de aula e que se torna coordenador/a pedagógico/a, embora, a priori, domine os saberes docentes, precisa ser capaz de transferir os saberes de uma área de atuação para outra. É 
imprescindível a clareza da mudança de papéis e o aprendizado de novos saberes específicos para a prática da coordenação pedagógica e da função de "educador/a do/a educador/a".

Baseado nos estudos de Therrien (2004) sobre os saberes da racionalidade da profissão do/a educador/a na sociedade contemporânea, podemos concluir que o/a coordenador/a pedagógico/a não é apenas um técnico de gestão educacional, mas, sobretudo, um/a educador/a do/a educador/a que, na prática, constrói cotidianamente sua competência profissional. Para o autor, são três as dimensões características do/a educador/a e que podemos aplicar aos saberes da coordenação pedagógica, como enumerado a seguir.

\section{- Os saberes da docência são múltiplos e heterogêneos}

O/a coordenador/a pedagógico necessita de saberes múltiplos e heterogêneos e que constituem parte insubstituível do repertório de saberes a dominar e dispor para o exercício de sua profissão. São os saberes dos campos da ciência dos quais os/as educadores/as não são profissionais propriamente ditos, mas sobre os quais devem ter conhecimentos. Trata-se dos saberes situados na confluência da sociologia, da psicologia, da antropologia, da filosofia, da história, da linguagem, das ciências exatas, da administração, da tecnologia, dentre outros. Não é necessário ao/a coordenador/a pedagógico/a o domínio dos conhecimentos dessas áreas todas, mas a capacitação para, a partir da interdisciplinaridade e da transposição didática, adquirir compreensão do mundo onde se situa e atua, construindo um saber contextualizado culturalmente. 
Há também os saberes próprios à gestão pedagógica propriamente dita, aqueles saberes que caracterizam e fundamentam os processos de ensino-aprendizagem do trabalho pedagógico e suas teorias, determinações legais e o conjunto de saberes necessários à gestão educacional, entendida como organização do trabalho, em termos de planejamento, coordenação, acompanhamento e avaliação do trabalho pedagógico.

\section{- 0/a coordenador/a pedagógico/a é um sujeito epistêmico e hermenêutico}

A competência profissional do/a coordenador/a pedagógico/a é inseparável da experiência e dos saberes que dela decorrem. Os saberes experienciais construídos no cotidiano de sua trajetória pessoal, de vida social e cultural, de formação e particularmente de trabalho profissional moldam a identidade dos repertórios de saberes disponíveis. Em sua prática, transforma os saberes acadêmicos e científicos, dando-lhe novas configurações, revelando um sujeito que, além de trabalhar com saberes, produz novos saberes. 0 desafio da transformação pedagógica de tais saberes em situações reais da prática revela um sujeito produtor de saberes.

Quando articula adequada e criativamente seu repertório de saberes num contexto e em situações de trabalho diversas, e em interação com outros sujeitos, realiza uma transformação pedagógica que é muito mais que uma transposição didática. A capacidade de retraduzir, transformar e reelaborar os saberes disponíveis no seu repertório de conhecimentos, sejam eles de origem científica sejam de outras fontes de experiência reflexiva no cotidiano de trabalho, implica numa postura 
de interação e comunicação, de diálogo e de argumentação pedagógica.

Assim, parafraseando Therrien (2004), a postura profissional de ação humana interativa de construção e produção de saberes e sentidos situa o/a coordenador/a pedagógico na categoria de sujeito epistêmico e hermenêutico.

- Os saberes do/a coordenador/a pedagógico/a revestemse de implicações éticas

O contexto no qual o/a coordenador/a pedagógico/a desenvolve e media os processos educacionais envolve, além dos saberes, fenômenos tais como complexidade, imediaticidade, incertezas, instabilidade, competitividade, ideologias dominantes, conflitos de valores, dentre outros. As direções dadas à mediação da prática educativa e do processo de formação continuada dos/as professores/as situam-se num patamar ético, porque envolvem tomadas de decisão, direcionamento, intervenções com teor político-ideológico e choques de interesses suscetíveis de afetar a concepção de vida e de mundo dos sujeitos envolvidos. Nesse contexto, a terceira dimensão que caracteriza o trabalho pedagógico desenvolvido por ele/a diz respeito às implicações éticas dessa função, para além dos aspectos da produção de saber.

A ética na perspectiva da emancipação humana é fundamental em qualquer profissão, estando fortemente presente na função do/a educador/a, e não pode privilegiar ou restringirse às posturas profissionais meramente dos professores/as atuantes em salas de aula. A autonomia relativa dada ao/a coordenador/a pedagógico/a leva-o/a, muitas vezes, à angústia 
de ter de defender os interesses da direção ou da Secretaria de Educação, em detrimento dos interesses e anseios dos/ as professores/as. No entanto, é essencial compreender que a dimensão ética do trabalho pedagógico tem suas raízes na formação do/a educador/a, no compromisso coletivo assumido individualmente por cada profissional quando abraçou a missão de educar, independentemente da função ou do cargo que exerça.

É na mobilização ética dos próprios saberes que o/a coordenador/a pedagógico/a consegue, através da linguagem, nas suas múltiplas formas, estabelecer a comunicação, o diálogo, a argumentação, a crítica, a construção de sentidos e o alcance de consensos, reflexos de verdades provisórias, mas transformadoras, levando à conscientização de que a educação, conforme preconiza Paulo Freire (1987), é um processo de aprendizagem da leitura e da escrita do mundo.

\section{REFERÊNCIAS}

ALARCÃO, Isabel. (Org.) Escola reflexiva e supervisão: uma escola em desenvolvimento e aprendizagem. Porto: Porto Editora, 2001.

ALMEIDA, P. C. A; BIAJONE. J. Saberes docentes e formação inicial de professores: implicações e desafios para as propostas de formação. São Paulo, Educação $e$ Pesquisa, v. 33. n. 2, p. 281-295, mai./ago. 2007.

ARROYO, Miguel G. Ofício de mestre: imagens e autoimagens. Petrópolis: Vozes, 2000. 
BRASIL. Secretaria de Educação Fundamental. Ministério da Educação. Referenciais para formação de professores. Brasília, 2002.

ENRICONE, Délcia. (Org.) Ser professor. Porto Alegre: EDIPURS, 2004.

FALCÃO FILHO, José Leão Marinho. Escola: ambientes, estruturas, variáveis e competências. Ensaio: avaliação e políticas públicas em educação. Belo Horizonte. Vol. 8. jul. /set. 2000.

FOUCAULT, Michel. Vigiar e punir. Petrópolis: Vozes, 1977.

FREIRE, Paulo. Pedagogia da autonomia: saberes necessários à prática educativa. São Paulo: Paz e Terra, 1996.

FREIRE, Paulo. Educação como prática da liberdade. São Paulo: Paz e Terra, 2002.

GAUTHIER, C. Por uma teoria da pedagogia: pesquisas contemporâneas sobre o saber docente. ljuí, Rio Grande do Sul: Editora Unijuí, 2013.

LEITE, Yoshie U. F. A formação de professores em nível de 2 grau e a melhoria do ensino da escola pública. 1995. Tese (Doutorado em Educação) - Faculdade de Educação, UNICAMP, Campinas, 1995.

MARX, Karl. Os pensadores. 2. ed. São Paulo: Abril, 1978.

PICONEZ, Stela. (Coord.) A prática de ensino e o estágio supervisionado. Campinas: Papirus, 1991.

PIMENTA, Selma Garrido. O pedagogo na escola pública.

São Paulo: Vozes, 1992. 
PIMENTA, Selma Garrido. O estágio na formação de professores - unidade, teoria e prática? São Paulo: Cortez, 1994.

PIMENTA, Selma Garrido. Pedagogia, ciência da educação? São Paulo: Cortez, 1996.

PIMENTA, Selma Garrido. (Org.) Saberes pedagógicos e atividade docente. São Paulo: Cortez, 2002.

SANTOS, Lucíola Licínio de Castro Paixão; OLIVEIRA, Nilza Helena de. O coordenador pedagógico no contexto de gestão democrática da escola. Disponível em: https:// www.google.com.br/o-coordenador-pedagogico-nocontexto-de-gestao-democratica-da-escola. Acesso em 2 mai. 2015.

SAVIANI, Dermeval. O trabalho como princípio educativo frente às novas tecnologias. In: FERRETI, Celso João et al. Novas tecnologias, trabalho e educação: um debate multidisciplinar. Petrópolis-RJ: Vozes, 1994.

SAVIANI, Dermeval. Os saberes implicados na formação do educador. IV Congresso estadual paulista sobre formação de educadores. Águas de São Pedro-SP, mai. 1996. Anais.

TARDIF, Maurice. Saberes profissionais dos professores e conhecimentos universitários: elementos para uma epistemologia da prática profissional dos professores e suas consequências em relação à formação para o magistério. Revista Brasileira de Educação, n. 13. Jan./ fev./mar./abr. 2000.

TARDIF, Maurice. Saberes docentes \& formação profissional. Petrópolis-RJ: Vozes, 2002. 
THERRIEN, Jacques. A pedagogia e o/a pedagogo/a na sociedade contemporânea: os saberes da racionalidade de uma profissão. Fórum Nacional de Pedagogia. Pedagogia: formação, identidades, práticas. Belo Horizonte, 11 a 14 jul. 2004. Anais.

TOMASI, Antônio. (Org.) Da qualificação à competência: pensando o século XXI. Campinas-SP: Papirus, 2004.

VASCONCELLOS, Celso dos Santos. Coordenação do trabalho pedagógico: do projeto político-pedagógico ao cotidiano da sala de aula. São Paulo: Libertad, 2002.

ZABALA, Antoni. A prática educativa: como ensinar. Porto Alegre: ArtMed, 1998.

\section{ABSTRACT}

This paper aims to fill a gap in academic productions regarding the knowledge and practices necessary to the educator to act at the pedagogical coordination of schools. Discussing various issues on this theme it seeks to promote a fruitful reflection in academic circles, especially in schools of education, offices in charge of training the educator. Is the pedagogical coordination a position or a function? Was the term "educational coordinator" constituted only into an attenuating to the negative connotation of the term "pedagogical supervisor", the one who occupied a mere controlling activity of the teaching pedagogical practice? What is expected today from the professionals who coordinate the pedagogical practice of teachers? What knowledge must they have? What is their main role? Can the pedagogical coordinator be considered the "educator of educators"? We expect to contribute to the 
debate and highlight the knowledge and practices demanded from this professional and what should be part of their training.

Keywords: Pedagogical coordination. Educator training. Knowledge and teaching practices.

\section{Raquel Quirino}

Pedagoga pelo Centro Universitário de Belo Horizonte (UNIBH); mestre em Educação Tecnológica pelo CEFET-MG; doutora em Educação pela Faculdade de Educação (FaE) da UFMG, com estágio pós-doutoral concluído na mesma instituição. Professora adjunta do CEFET-MG, no qual atua como docente no Programa de Pós-Graduação em Educação Tecnológica (PPGET) e no Programa Especial de Formação Pedagógica de Docentes (PEFPD). Atua como pesquisadora na área de formação e qualificação profissional, dialogando, sobretudo, com as relações de gênero na Ciência e Tecnologia (C\&T), no trabalho e na educação profissional e tecnológica. Na formação docente, atua nas áreas de Didática e Estágio Supervisionado. quirinoraquel@hotmail.com 